\title{
Radiative Forcing of Asian Dust Determined from the Synergized GOME and GMS Satellite Data-A Case Study
}

\author{
Maria João COSTA \\ Department of Physics and Évora Geophysics Centre, University of Évora, Évora, Portugal \\ Byung- Ju SOHN \\ School of Earth and Environmental Sciences, Seoul National University, Seoul, Korea \\ Vincenzo LEVIZZANI \\ Institute of Atmospheric Sciences and Climate (ISAC-CNR), Bologna, Italy \\ and \\ Ana Maria SILVA \\ Department of Physics and Évora Geophysics Centre, University of Évora, Évora, Portugal
}

(Manuscript received 25 April 2005, in final form 29 September 2005)

\begin{abstract}
Aerosol optical characteristics of Asian dust are studied by combining Global Ozone Monitoring Experiment (GOME) data, with Geostationary Meteorological Satellite (GMS-5) visible data, collected during a Yellow Sand event occurred on 7 April 2000. Retrieved results were compared with those from solar aureole measurements at Anmyon-Do, Korea. It was shown that the single scattering albedo of Asian dust can be as low as 0.76 , much smaller than the generally known values of 0.9 in the Asian dust source region, such as Dunhuang or 0.93 for Saharan dust. This finding suggests that Asian dust can be much absorbing aerosols. The overall atmospheric forcing efficiency (radiation fluxes per unit aerosol optical thickness at $0.5 \mu \mathrm{m}$ ) of Asian dust observed on 7 April 2000, is about $102 \mathrm{Wm}^{-2}$ in the atmospheric layer, and $-116.9 \mathrm{Wm}^{-2}$ at the surface. These results strongly indicate that the regional surface and atmospheric radiation energy budget, can be significantly altered by the presence of Asian dust.
\end{abstract}

\section{Introduction}

Aerosols in East Asia are presumed to be very different from other regions. There are many absorbing soot, and organic aerosols from coal or biomass burning over the Asian and Pa-

Corresponding author: B.J. Sohn, School of Earth and Environmental Sciences, Seoul National University, Mail Code NS80, Seoul, 151-747, Korea. E-mail: sohn@snu.ac.kr

(C) 2006, Meteorological Society of Japan cific regions (Chameides et al. 1999). Increased fossil fuel burning, caused by rapid economic growth in many Asian countries, results in more $\mathrm{SO}_{2}$, organic matters, and soot aerosols being emitted into the East Asian atmosphere. Moreover, Asian dust particles, which could lead to both cooling by scattering sunlight back to space, and warming by absorbing solar and infrared radiation, make the Asian aerosol situation more complicated (Sokolik and Toon 1999). Heavy dust storms, called Yellow Sand 
events in East Asia, can significantly perturb the atmospheric radiation budget (Kim et al. 2005). Moreover, in-situ and satellite remotesensing measurements have shown that dust particles from the Asian continent could be transported beyond the Pacific Ocean to the U.S. western seaboard (Husar et al. 2001), indicating that dust influences are not just confined within the surrounding East Asian region. Because of such a vital interest in the possible impact of Asian dust on local or global climate, there is much need to investigate the optical characteristics of Asian dust particles.

On the other hand, the frequency of dust storms appears to change, in particular due to the anthropogenic influences on the environment (Sun et al. 2000; Yoshino 2002). Accordingly it is natural to ask whether there is a reliable way to monitor optical properties and forcing magnitudes, from which the consequence of Asian dust for the climate can be studied. In this paper, we will examine a synergistic way to use geostationary satellite information to determine the aerosol optical properties of Asian dust.

New generation Low Earth Orbit (LEO) satellite sensors present in general a good spectral resolution for aerosol studies, allowing measurement of spectral regions mostly devoid of gas absorption (King et al. 1999). In particular, the Global Ozone Monitoring Experiment (GOME) spectrometer (Burrows et al. 1999), on board the European Remote Sensing Satellite (ERS-2), presents high spectral resolution measurements in the ultraviolet (UV), and visible (VIS) regions of the electromagnetic spectrum, significant for the derivation of aerosol properties and atmospheric aerosol load (Torricella et al. 1999; Costa et al. 2002; Costa 2004). Nevertheless, the inadequacy of LEO sensors to follow the evolution of a phenomenon is evident since they overpass nearly the same area once a day at the most.

By contrast, geostationary (GEO) satellites ensure a more adequate temporal and spatial coverage for monitoring purposes. However, most of the sensors aboard GEO systems present only broadband spectral channels, allowing the retrieval of no more than one climaterelevant aerosol quantity, usually the aerosol optical thickness (AOT) (Moulin et al. 1997; Masuda et al. 2002). In addition, measure- ments by visible sensors aboard geostationary satellites may not adequately represent the atmospheric state at the time of satellite overpass, because of broadband characteristics. This can introduce considerable errors on the AOT retrievals. In consequence, significant uncertainties affect the direct shortwave aerosol radiative forcing (DSWARF) estimates.

Recent studies (Costa et al. 2004a; Costa 2004b), however, demonstrated that the synergistic use of LEO (GOME), and GEO satellite sensors, can overcome the aforementioned limitations of both types of instruments (LEO and GEO) for an effective aerosol optical property, during strong aerosol events over the ocean (Costa et al. 2002). Key features of the method are the improved accuracy of the aerosol characterization with respect to methods based exclusively on GEO measurements, and extension of the spatial and temporal coverage of LEO retrievals to the GEO spatio-temporal scale.

The method has already been successfully applied to several case studies using the GEO meteorological satellite Meteosat (Costa et al. 2004b). By the same token it is interesting to examine how the Asian dust event can be monitored from a geostationary satellite, in conjunction with a LEO satellite. In this study, aiming at dust characterization, we combine GOME data with Japanese GMS-5 measurements, to estimate the top of the atmosphere (TOA), surface and atmospheric DSWARF over the geographical area where the event occurs. Derived optical properties are compared with those retrieved from the ground-based solar radiation measurements. In addition, the modelled TOA SW flux is compared with the Clouds and the Earth's Radiant Energy System (CERES; Wielicki et al. 1996) TOA flux product, for a quality check of the solar flux modeling.

\section{Methodology}

The detailed retrieval method for aerosol optical properties over the ocean using the GOME is found in Costa et al. (2004a). In this section we provide a brief summary of retrieval methods for aerosol optical properties and radiative forcing.

\subsection{Aerosol characterization}

As a first step, GOME measurements are analysed in order to select spatially homogenous 
Table 1. Lower and upper variation limits (given in bold) of the size distribution, complex refractive index and AOT at $0.55 \mu \mathrm{m}$ parameters. Also indicated are the coarse mode radius and coarse mode percentage number density of particles.

\begin{tabular}{|c|c|c|c|c|c|c|}
\hline \multirow{2}{*}{$\begin{array}{l}\text { Aerosol } \\
\text { type }\end{array}$} & \multirow[b]{2}{*}{ Mode } & \multirow{2}{*}{$\begin{array}{l}\text { Modal } \\
\text { radius } \\
(\mu \mathrm{m})\end{array}$} & \multirow{2}{*}{$\begin{array}{l}\text { Percentage } \\
\text { number } \\
\text { density of } \\
\text { particles } \\
\text { (Pndp) }\end{array}$} & \multicolumn{2}{|c|}{$\begin{array}{l}\text { Spectral complex } \\
\text { refractive index }\end{array}$} & \multirow{2}{*}{$\begin{array}{c}\text { Aerosol } \\
\text { optical } \\
\text { thickness }\end{array}$} \\
\hline & & & & $0.35-0.50$ & $0.70-0.86$ & \\
\hline \multirow{2}{*}{$\begin{array}{l}\text { Desert } \\
\text { dust }\end{array}$} & Fine & $0.09-0.6$ & $\begin{array}{l}\text { Pndp (fine): } \\
96.0-100.0\end{array}$ & \multirow[b]{2}{*}{$0.001-0.03$} & \multirow[b]{2}{*}{$0.0008-0.025$} & \multirow[b]{2}{*}{$0.4-2.0$} \\
\hline & Coarse & 2.5 & $\begin{array}{l}\text { Pndp (coarse): } \\
\text { 100.0-Pndp } \\
\text { (fine): }\end{array}$ & & & \\
\hline
\end{tabular}

pixels over the ocean, which is rather difficult due to the spectrometer's low spatial resolution (pixel size is $320 \times 40 \mathrm{~km}^{2}$ ) and its lack of infrared information, which is most relevant for cloud, land and aerosol detection. These are overcome by collocating the GOME image with GMS-5 classified images (clouds, aerosol event or background aerosol) in space and time (within a maximum15-minute difference). Cloud classifications are obtained by applying a statistical algorithm of Porcù and Levizzani (1992) that uses VIS and infrared (IR) measurements.

The absorption of radiation by atmospheric gases may interfere with the processes of scattering and absorption by aerosols, so that the selection of wavelengths not affected by gases is important. Torricella et al. (1999) provides such a selection not much affected by gases from the GOME high resolution spectra, i.e., $0.361,0.421,0.753$ and $0.783 \mu \mathrm{m}$.

Aerosols are here assumed to be characterized by a bimodal log-normal size distribution with a fine and a coarse mode, and a complex refractive index common to both modes (see Table 1). The measured spectral reflectance corresponding to each selected GOME pixel is compared to the simulated spectral reflectance contained in a look-up table (LUT) that is calculated by altering the modal radius and particle percentage density for the fine mode, the imaginary part of the refractive index in the two spectral regions, and AOT at the reference wavelength of $0.55 \mu \mathrm{m}$. The spectral regions considered for the imaginary refractive index are $0.35-0.50 \mu \mathrm{m}$ and $0.70-0.86 \mu \mathrm{m}$. The
GOME four channel measurements in the UVVIS spectrums are used to find the "best" aerosol model from the pre-constructed LUTs, which is considered an effective aerosol model, since it reproduces the measured spectral reflectances. There are no iterative processes to find the best fit, but instead precalculated LUTs are used. The aerosol type is assumed a priori, as well as the surface reflectance and atmospheric vertical profiles of the gaseous species. The "best" aerosol model is retained valid for a subsequent use with GEO data, in order to provide a useful and effective monitoring of the AOT and aerosol radiative forcing. Therefore, an aerosol characterization from this approach is supposedly more realistic than those available from literatures. The mean size distribution, and spectral complex refractive index, for Asian dust are used as initial parameters for the GOME LUT development, and those aerosol climatologies are obtained from the three year (1998-2000) measurements of solar radiation for the Asian dust at AnmyonDo, Korea-see Kim et al. (2004) for the dust analysis. The variation limits of the aerosol parameters for the refinement are shown in Table 1.

It should be pointed out that the method was developed by assuming that the spatial extension of aerosol plumes under study is sufficiently large, to encompass several GOME pixels. Although the ground spatial resolution of GOME is certainly coarse, it is considered sufficient for the aerosol-type retrieval at the local scale, since aerosol type varies consider- 
ably less than the aerosol loads over a given area.

The pseudo-inversion is performed over all selected GOME pixels to retrieve several size distributions, complex refractive indices and optical thickness (at the reference wavelength of $0.55 \mu \mathrm{m}$ ) at the GOME spatial scale, which characterize the mixture of aerosols present in the atmosphere for each space-time measurement. A subsequent spatial/temporal analysis of these inversion results is carried out, including the separation in terms of the initial classification of each pixel (e.g., background aerosol or other events). Retrieval of size distributions, and complex refractive indices for each of these classes, is then used to derive the corresponding spectral aerosol optical quantities, namely the extinction, scattering and absorption coefficients, phase function, single scattering albedo, and asymmetry parameter at the wavelengths of $0.400,0.488,0.515,0.694$ and $0.860 \mu \mathrm{m}$. These quantities are calculated by assuming spherical aerosol particles, and using the GOME-derived size distributions and complex refractive indices as inputs for Mie scattering calculations. The resultant aerosol optical quantities are then averaged, after rejecting pixels showing variations larger than $30 \%$ with respect to the mean value. This permits the retrieval of effective aerosol optical quantities for a geographical area at the time under study.

An LUT of the GMS-5 VIS broadband radiance $(0.55-0.90 \mu \mathrm{m})$ is calculated using the mean aerosol class, obtained from the inversion of GOME spectral reflectance, considering all possible geometric conditions associated with the Sun, the GEO satellite and the seven AOT values at $0.55 \mu \mathrm{m}(0.0,0.1,0.2,0.5,1.0,1.5$, 2.0). These seven AOT values are chosen to integrate the LUT and are considered enough to calculate any AOT value between 0.0 and 2.0. Subsequently, the AOT at the reference wavelength of $0.55 \mu \mathrm{m}$ is computed at each GEO pixel, by interpolating the $\mathrm{GEO}$ radiances stored in the LUT to the GEO radiance measurement. In so doing we can construct AOT maps suitable for the space-time monitoring of aerosol loads over the ocean.

\subsection{Direct $S W$ aerosol radiative forcing}

Downwelling, and upwelling SW fluxes at the surface $\left(F_{\downarrow}^{S U R F}\right.$ and $\left.F_{\uparrow}^{S U R F}\right)$ as well as upwelling
SW flux at the TOA $\left(F_{\uparrow}^{T O A}\right)$, are calculated for solar zenith angles (from $0^{\circ}$ to $85^{\circ}$ with a step of $\left.5^{\circ}\right)$, and AOT values at $0.55 \mu \mathrm{m}(0.0,0.2,0.5$, $1.0,1.5,2.0)$, in order to build the flux LUTs. The aerosol properties are specified by the optical quantities derived from GOME spectral measurements, ensuring that the used aerosol characterization represents the atmospheric conditions for the geographical area and period of the study. The SW spectral range considered for the flux calculation is from 0.25 to $4.0 \mu \mathrm{m}$. After determining the solar zenith angle, the AOT previously retrieved from the GEO satellite data is compared to the AOTs contained in these LUTs, estimating solar fluxes and then the DSWARF. As for the surface spectral reflectance needed for the calculation of aerosol radiative forcing, we use values typical of sea water, contained in database of the $6 \mathrm{~S}$ model (Vermote et al. 1997).

The DSWARF, i.e., the change in the atmospheric radiation balance at the surface, and the TOA $\left(\triangle F^{S U R F / T O A}\right)$, due to the presence of aerosol particles (through scattering and/or absorption of radiation) is in turn estimated, i.e.:

$$
\Delta F^{S U R F / T O A}=F_{n e t(d u s t)}^{S U R F / T O A}-F_{\text {net(clean })}^{S U R F / T O A}
$$

In Eq. (1), $F_{\text {net }}^{S U R F / T O A}$ is the SW net flux at the surface or at the TOA, and is obtained from the difference between the downwelling and the upwelling fluxes, as in the following equation.

$$
F_{\text {net }}^{S U R F / T O A}=F_{\downarrow}^{S U R F / T O A}-F_{\uparrow}^{S U R F / T O A}
$$

The DSWARF of an atmospheric column $\left(\Delta F^{A T M O S}\right)$ is also estimated, i.e.:

$$
\Delta F^{A T M O S}=\Delta F^{T O A}-\Delta F^{S U R F}
$$

\section{Analysis of 7 April 2000 dust event}

During the spring, a large amount of Asian dust is uplifted from northern China, and transported to a wide region under prevalent westerlies in mid-latitudes. These dusts significantly increase the atmospheric turbidity over East Asia and adjacent Pacific regions in spring, possibly altering the radiation balance over those regions. On 7 April 2000, a strong dust storm originated in the Gobi desert, and swept the Yellow Sea and continued to move east over the geographical region shown in Fig. 1. In addition, the smoke from forest fires in 


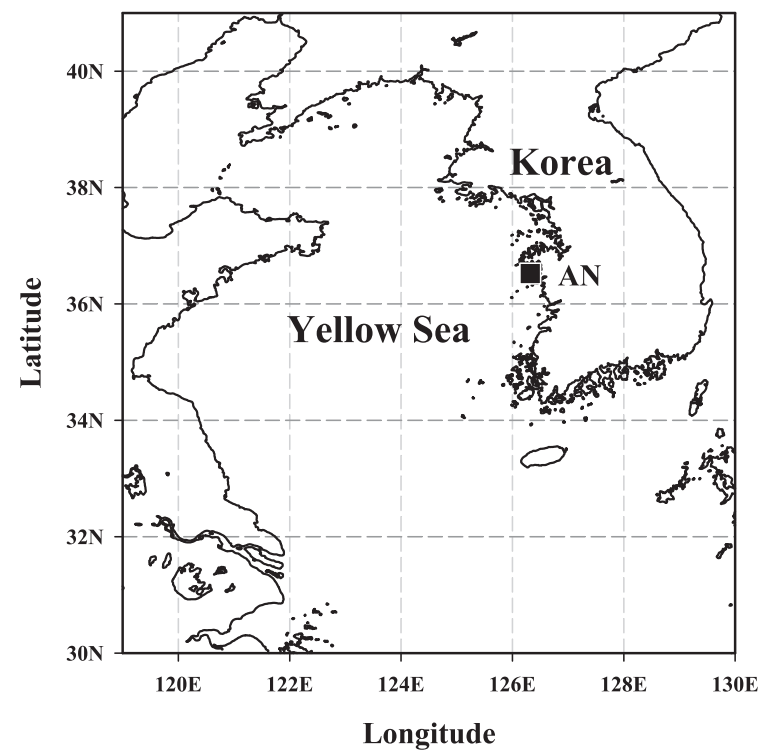

Fig. 1. Map of the geographical area considered for the study of the Asian dusts over the Yellow Sea. The black square indicates the location of the ground measurement site used for comparison, Anmyon-Do (AN).

Korea appears to mix with dusts off the east coast of Korea. However, the present study concentrates only on the dust situated over the Yellow Sea, excluding any mixture of different aerosol types. Images of Japan's operational meteorological satellite-GMS-5 (VIS: 0.55$0.90 \mu \mathrm{m}$, and IR: $11.5-12.5 \mu \mathrm{m}$ spectral channels) on 7 April 2000 are collected hourly from 0030 to 0930 UTC (0930 to 1830 Korean LST). Space-time nearest GOME orbits are also collected. GOME spatially homogeneous pixels are selected using GMS-5 VIS and IR spacetime coincident imagery to detect clouds. Aerosol optical properties are obtained from the GOME spectral measurements inversion, and subsequently used in combination with the GMS-5 VIS reflectance measurements to retrieve AOT at $0.55 \mu \mathrm{m}$ and DSWARF over the Yellow Sea. The region considered for the comparisons of the AOT and DSWARF with the ground-based measurements, is represented on the map of Fig. 1 by a black square (and noted as 'AN'). It corresponds to an area of $0.25^{\circ} \times 0.25^{\circ}$ in latitude and longitude, centred at the geographical coordinates of Anmyon-Do $\left(36.52^{\circ} \mathrm{N}, 126.32^{\circ} \mathrm{E}\right)$, the Korean site where the ground measurements of solar radiation were taken.

Direct and diffuse solar radiation measurements were carried out using a sky radiometer (POM-01L; Prede Co. Ltd.) at seven wavelengths of $315,400,500,675,870,940$, and $1020 \mathrm{~nm}$ at Anmyon-Do. The aerosol optical thickness, single-scattering albedo at five wavelengths (400, 500, 675, 870, and $1020 \mathrm{~nm}$ ), Ångström exponent, and volume size distribution $\left[d V(r) / d \ln r\left(\mathrm{~cm}^{3} \mathrm{~cm}^{-2}\right)\right]$ were retrieved using the SKYRAD.pack version 3 software (Nakajima et al. 1996), which consists of a radiative transfer code as well as linear and nonlinear inversion components. A brief summary of the inversion method is found in Aoki and Fujiyoshi (2003) and Kim et al. (2005) along with some results from the sensitivity test for uncertainty analysis.

\section{Results}

Aerosol quantities retrieved at the GOME pixel scale (spectral single scattering albedo, phase function and Angström exponent), as well as AOT at the GMS-5 spatial scale are compared with the respective quantities derived from the ground-based radiation measurements at Anmyon. Note that the aerosol properties derived from GOME measurements correspond to the whole area illustrated in Fig. 1 and not exclusively to the area around Anmyon-Do (the black square in the map of Fig. 1). Nevertheless all GOME measurements used for the retrievals correspond to dusty pixels. Therefore the aerosol properties retrieved from GOME measurements should represent mean dust aerosol conditions that occurred in the area on 7 April 2000. Assuming the Asian dust situated in this study region possesses spatial homogeneity and thus maintains its optical and physical characteristics, GOME-derived aerosol properties are compared with the results obtained from sky radiation measurements at Anmyon.

\subsection{Characteristics of Asian dust aerosol derived from GOME}

Spectral single scattering albedos obtained from the GOME inversions are compared with those measured at Anmyon-Do and taken from the Shettle (1984) dust model, as shown in Fig. 


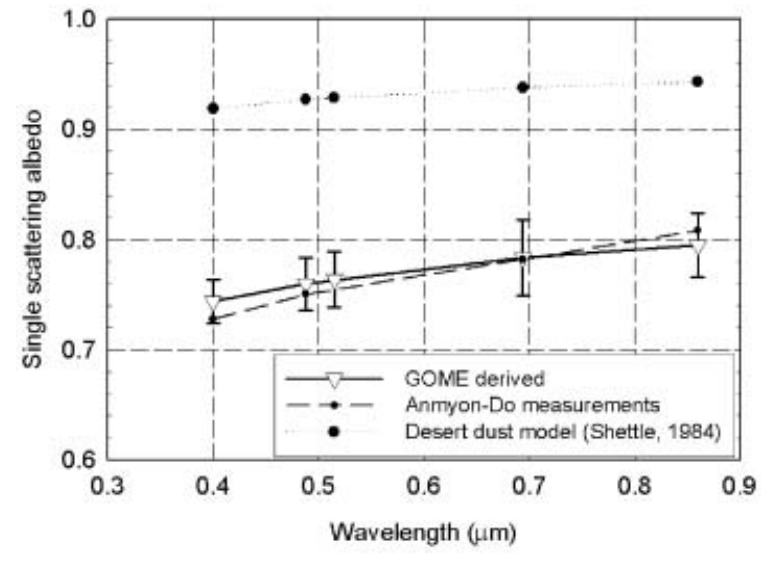

Fig. 2. Spectral single scattering albedos (at $0.400,0.488,0.515,0.694$ and $0.860 \mu \mathrm{m})$ for Asian dusts over the Yellow Sea. The vertical error bars represent the standard deviation of the GOME derived single scattering albedo (around 0.04).

2. The vertical error bars represent the standard deviation of the GOME derived single scattering albedo (around 0.04). It is noted that spectral single scattering albedos derived from GOME spectra for the Asian dusts over the Yellow Sea are in good agreement with the ground-based measurements taken at AnmyonDo, Korea. There is a slight overestimation of GOME results in the blue spectral region and an underestimation in the red, but both results are very close and within the GOME-derived error bars. As for the results from the Shettle (1984) desert model, the discrepancy is substantial. In fact, the derived and measured single scattering albedos for 7 April 2000 case are extremely low, and found to be much smaller than those observed in source regions, i.e., around 0.9 at $0.5 \mu \mathrm{m}$ in Dunhuang area (Kim et al. 2005). This may be an indication that Asian dust may interact with industrial or urban aerosols (containing black carbons), while dust moves through heavy pollution areas of China, altering its properties through the mixing processes (Clarke et al. 2004; Kim et al. 2005).

Phase functions derived from GOME measurements are compared with measurements at Anmyon-Do, and with those in Shettle (1984)-Fig. 3. The phase function is repre-

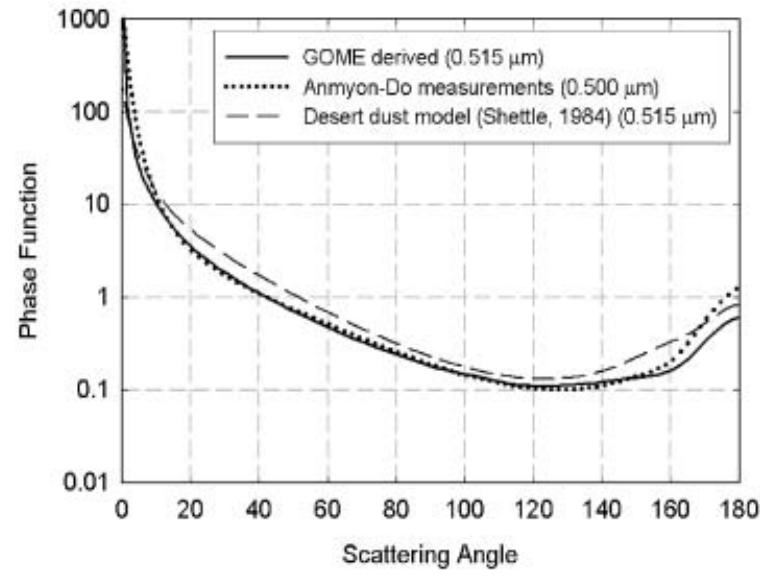

Fig. 3. Phase function for the Asian dusts over the Yellow Sea.

sented for two close wavelengths. The GOME derived phase function refers to the $0.515 \mu \mathrm{m}$ wavelength, and the corresponding campaign measurements are available at a wavelength of $0.5 \mu \mathrm{m}$. The values from the Shettle (1984) model are also presented. The comparison of phase function between results and groundbased measurements reveals a fine agreement, except for the small differences found for scattering angles greater than $160^{\circ}$. The desert dust literature model tends in general to overestimate the values with respect to the measurements.

It might be interesting to compare the asymmetry parameter (g) retrieved from GOME data with that from ground aureole measurements. GOME retrievals show 0.70 of the asymmetry parameter at $515 \mathrm{~nm}$, which is similar to 0.71 for desert dust model of Shettle (1984). The $\mathrm{g}$ values at $500 \mathrm{~nm}$ from the measurements at Anmyon were around 0.80 until 0500 UTC, in which AOTs greater than 1.0 were observed, and smaller 0.72 after 0600 UTC. Such discrepancy between the GOME retrieval, and SKYRAD.pack results, appear to be in part due to the large GOME foot print $\left(320 \times 40 \mathrm{~km}^{2}\right)$, which may represent average quantity of aerosol parameters over a fairly large area.

The GOME-derived Ångström exponents are also compared with ground measurements (Fig. 4). The value obtained from the satellitebased algorithm (GOME measurements) is con- 


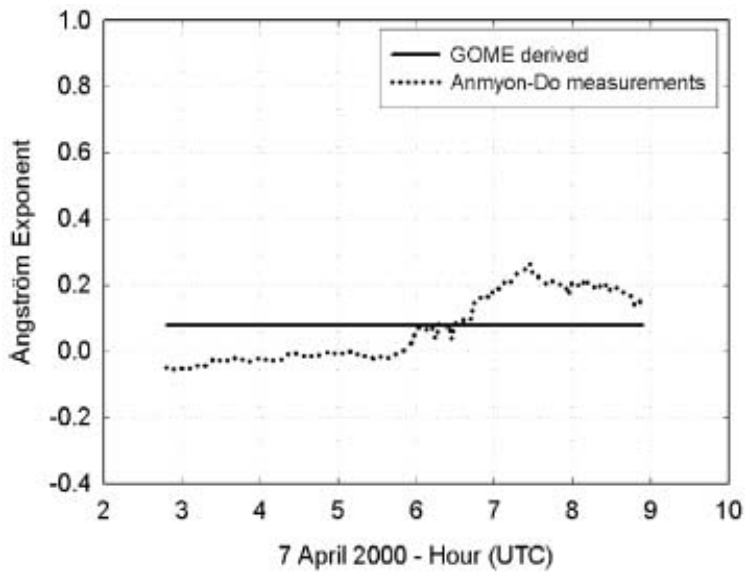

Fig. 4. Ångström exponents for the Asian dusts over the Yellow Sea. stant, since it is a function of the derived aerosol model in which the Angström exponent is invariant with time and thus remains unchanged for the case under study. The Angström exponent obtained from ground measurements for the Asian dust event shows a negative value for the first part of the day, then it increases to a positive value after 0630 UTC (1530 LST). The analysis of the AOT hourly variation in Fig. 5 indicates that after 0230 UTC (1130 LST) the dust area moves south from Anmyon-Do, therefore the higher Angström exponent later in the day is not solely due to dust, but due to other mixed types of aerosols. Nevertheless the agreement with the GOME-derived value (0.08) is quite good.

\subsection{Aerosol optical thickness derived from GMS data}

Figure 5 shows the hourly AOT distribution over the area shown in Fig. 1. The AOTs are de-
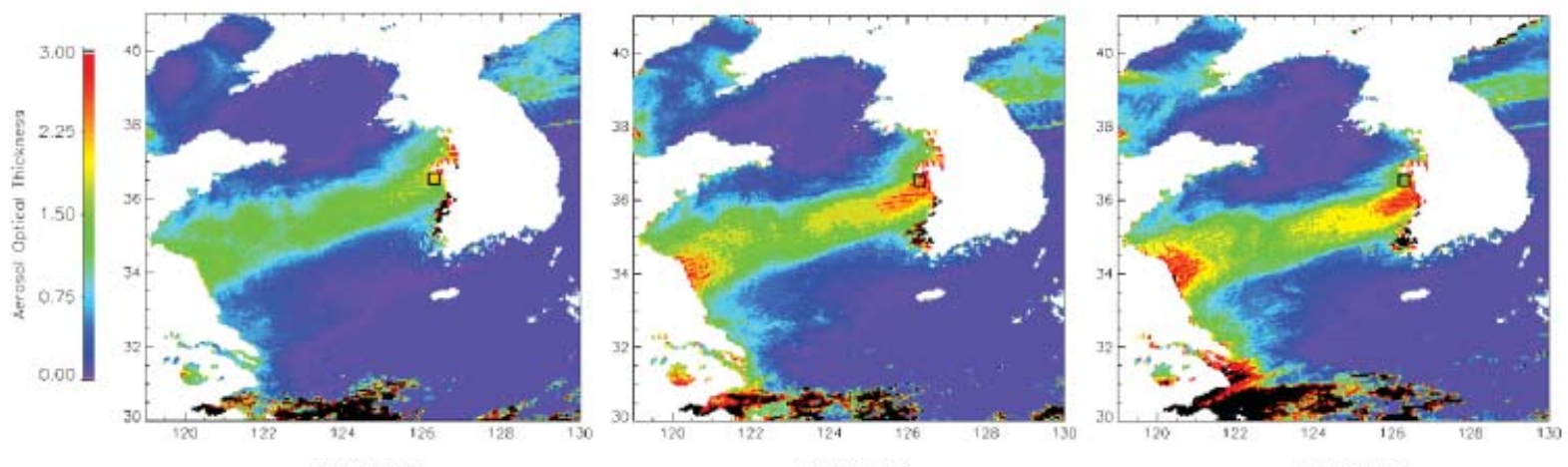

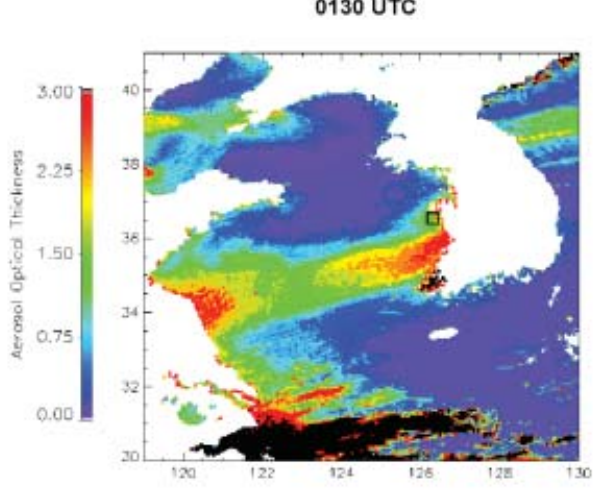

0423 UTC

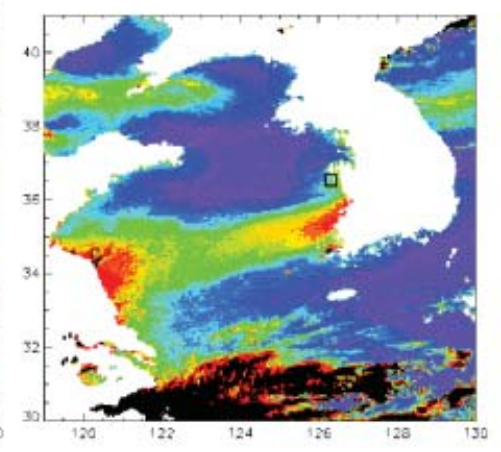

0530 UTC

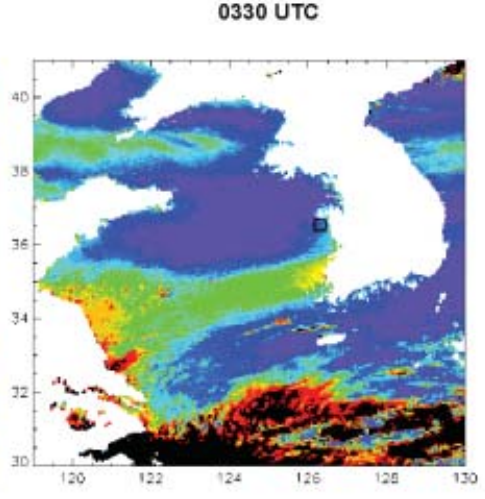

0630 UTC

Fig. 5. Geographical distribution of hourly AOTs at $0.55 \mu \mathrm{m}$ derived from GMS-5 visible reflectance for 7 April 2000 over the Yellow Sea. The Anmyon-Do ground site is represented by the square. Pixels contaminated by clouds are represented in black and land in white. Nine hours are added to UTC for the Korean local time. 


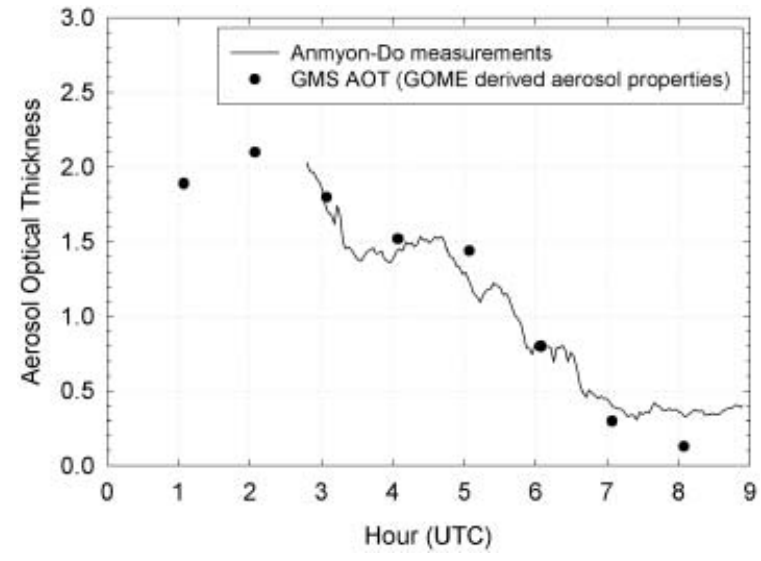

Fig. 6. Time evolution of GMS derived AOTs at $0.55 \mu \mathrm{m}$ (dots) along with surface measurements at Anmyon (line) for the 7 April 2000. Korean local time is obtained by adding 9 hours to the UTC.

rived at the reference wavelength of $0.55 \mu \mathrm{m}$, from GMS-5 visible reflectance measurements (see Section 2.1), using the aerosol properties obtained from GOME spectral inversions. The region considered for the comparison of retrieved AOT with ground-based measurements is delimited on maps by the square which corresponds to an area of $0.25^{\circ} \times 0.25^{\circ}$ in latitude and longitude, centred on the geographical coordinates of Anmyon-Do. The dust aerosol plume stretching from East China toward Korea can be well distinguished in any of the maps of Fig. 5. From the images it is evident that the plume moves from North to South with time. Also detected is an increase in dust contamination in Bohai Bay along the day. The AOTs inside the area defined by the square are arithmetically averaged (excluding cloud- and land-contaminated pixels), and compared to ground measurements of the AOT at AnmyonDo. Figure 6 shows the AOT comparison for 7th April 2000, as a function of UTC time. Measurements and results show a very good agreement, with absolute differences always lower than 0.2. Moreover, the satellite retrieval closely reproduces the trend of ground-based measurements during the day.

\subsection{Estimation of aerosol radiative forcing}

The TOA SW flux modelled with a radiative transfer code 6S (Vermote et al. 1997) is com-

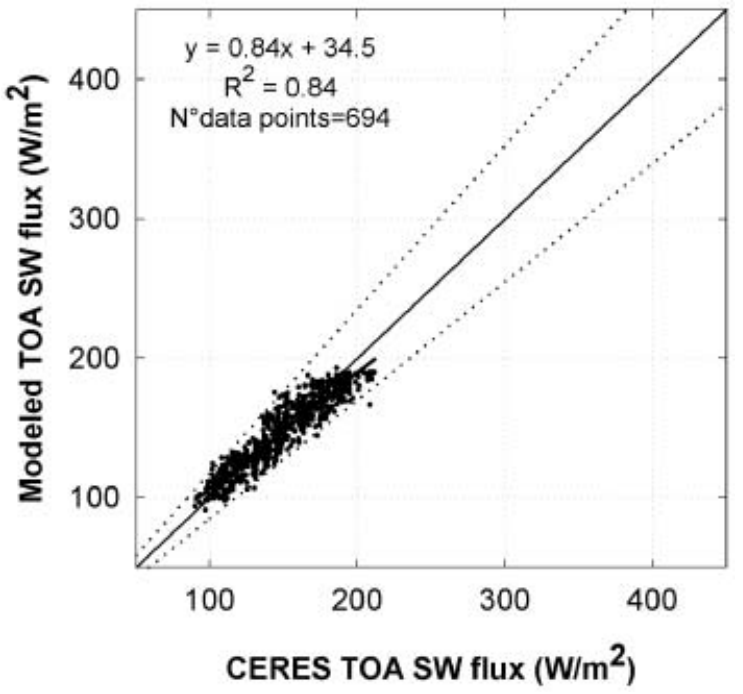

Fig. 7. Scatter plots of modelled TOA SW fluxes versus CERES measured TOA SW fluxes for the geographical area presented in Fig. 1. The dotted lines represent the $\pm 15 \%$ error range.

pared with the CERES TOA SW flux product, as a way of verifying the radiative transfer calculations, and checking the validity of the calculated LUTs. Results are given in Fig. 7. Each data point in Fig. 7 represents an average over a $0.25^{\circ}$ by $0.25^{\circ}$ latitude-longitude grid box for clear pixels over the ocean. The model results show a slight underestimate with respect to CERES measured TOA flux. Nevertheless, the measurements and the corresponding modelled data are generally in good agreement; $98 \%$ of the modelled values agree with CERES data within a $15 \%$ error (the range enveloped by dotted lines in the plots).

The TOA DSWARF is then retrieved over the study areas, using the AOT values previously estimated from GMS-5 measurements, and the LUTs calculated using the aerosol properties retrieved from GOME (Section 2.2). Figure 8 shows the variation of the DSWARF at the TOA and at the surface, with the AOT at the reference wavelength of $0.55 \mu \mathrm{m}$ calculated from GMS-5, with GOME-derived aerosol properties. Each curve represents SW aerosol radiative forcing, with AOT at a given sun-satellite geometry, and solar illumination at AnmyonDo. It is noted that the curve fluctuates mainly 


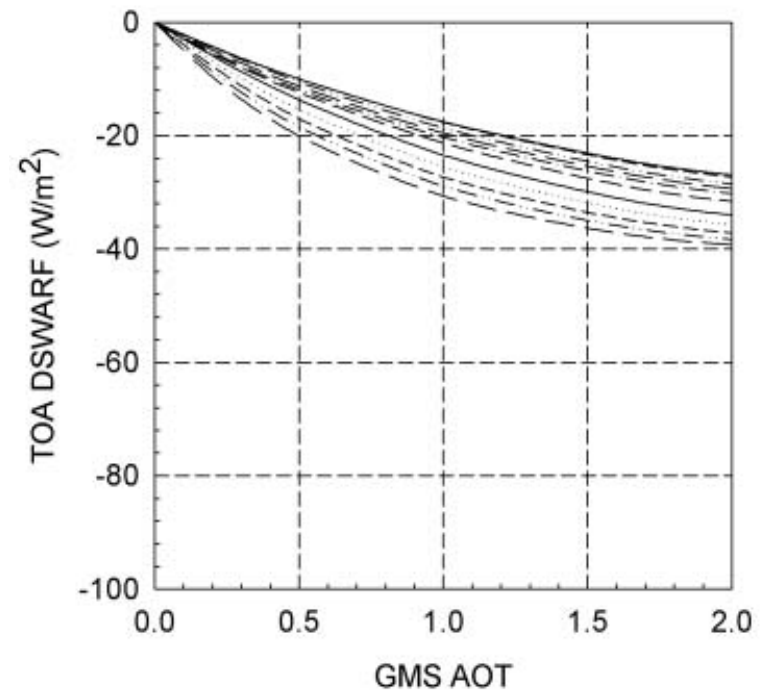

a)

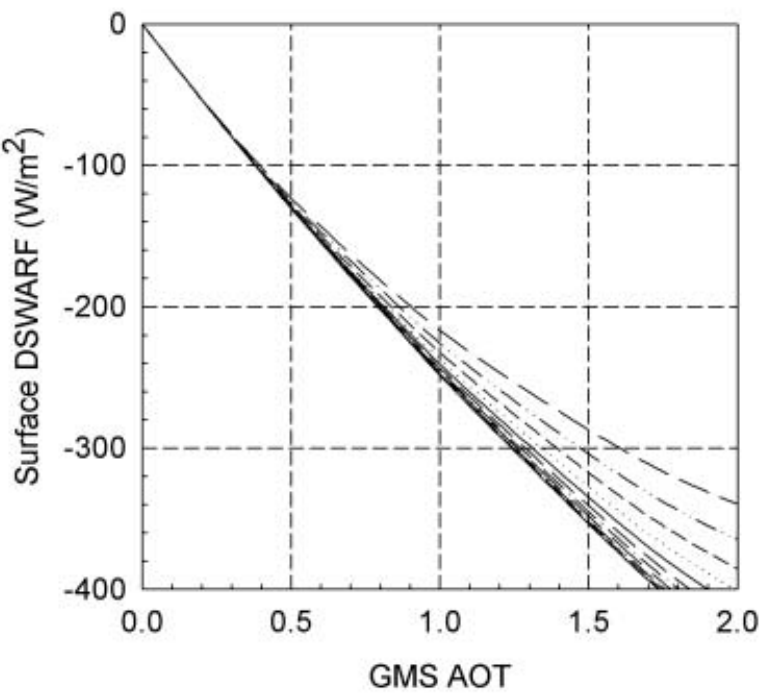

b)

Fig. 8. Scatter plots of the TOA and surface DSWARF versus AOT at the reference wavelength of $0.55 \mu \mathrm{m}$, for the geographical area in Fig. 1. Graph a) represents the TOA and b) the surface. The points in a curve correspond to pixels in the GMS-5 imagery and what varies (between curves) is time during the event and geometry of the illumination.

with different solar zenith angle, because the GMS satellite viewing angle is nearly invariant.

The mean value of the TOA DSWARF obtained for the area considered around AnmyonDo is $-21.5 \mathrm{~W} \mathrm{~m}^{-2}$, and the TOA DSWARF per unit optical thickness (i.e., forcing efficiency $\beta$ ) is found to be $-15.3 \mathrm{~W} \mathrm{~m}^{-2}$. As for the surface DSWARF, results obtained in the area around Anmyon-Do are $-164.5 \mathrm{~W} \mathrm{~m}^{-2}$, with $\beta=$ $-116.9 \mathrm{~W} \mathrm{~m}^{-2}$. The overall radiation convergence in the atmosphere is $143 \mathrm{Wm}^{-2}$, and $\beta$ for the atmosphere is about $102 \mathrm{Wm}^{-2}$, indicating that the Asian dust observed at AnmyonDo, Korea can absorb a large amount of solar energy - note the AOT magnitude as large as 2 at 0200 UTC bringing in atmospheric solar absorption up to $290 \mathrm{Wm}^{-2}$ at one moment.

\section{Conclusions and discussion}

A method for deriving the aerosol optical properties (at $0.400,0.488,0.515,0.694$ and $0.860 \mu \mathrm{m}$ ), and monitoring the AOT (at $0.55 \mu \mathrm{m}$ ) and DSWARF (Costa et al. 2004a) was applied to measurements from Japan's operational meteorological satellite (GMS-5, positioned at $0^{\circ}, 140^{\circ} \mathrm{E}$ ), to study the radiative forcing induced by one Asian dust event which occurred on 7 April 2000, and its consequence in the radiation budget.

The variation of AOTs, and the geographical variation of plume location, demonstrate the importance of developing monitoring capabilities from available satellite sensors. Such information would be completely lost by methods based exclusively on LEO sensors, which would be scanning the area only once in this period, depending on the time of the satellite overpass.

It is found that the radiative forcing efficiencies of Asian dust that occurred on 7 April 2000 are $-15.3 \mathrm{~W} \mathrm{~m}^{-2}, 102 \mathrm{Wm}^{-2},-116.9 \mathrm{Wm}^{-2}$ at the TOA, in the atmospheric layer, and at the surface, respectively. From the composite of sky radiation measurements for Asian dust events at Anmyon, Kim et al. (2005) reported that radiative forcing efficiencies at Anmyon could be $-26 \mathrm{Wm}^{-2}, 65 \mathrm{Wm}^{-2}$, and $-91 \mathrm{Wm}^{-2}$ at the TOA, atmosphere, and surface, respectively. In comparison to the mean forcing, the much larger magnitude of the atmosphere (and thus the much larger cooling at the surface), seems to be attributable to the lower single scattering albedo around 0.76 at $0.5 \mu \mathrm{m}$. Kim et al. (2005) reported 0.86 of the mean single scattering albedo for Asian dust at Anmyon. 
The magnitude found in this study appears to be considerably smaller than that around 0.9 found in Dunhuang during the dusty spring time-see Kim et al. (2005) for details. Recent emission inventories of various pollution materials have been reported in Streets et al. (2003), in which Northeast China is found to be one of the epicenters of pollution emission. This lower single scattering albedo might be due to extensive mixing with polluted air masses containing sulfates, nitrates, and black carbons in Northeast China during the dust movement, as suggested in Clarke et al. (2004) and Kim et al. (2005).

Importantly the lower single scattering albedo during the dust event manifests the importance of aerosols in climate, because the larger absorption effect of the aerosols can significantly alter the radiation balance over the region. The values found in this study suggest that dust can induce a great deal of radiative cooling effect on the surface, while inducing a significant warming effect within the atmosphere, due to the lower single scattering albedo when dust is mingled with pollution materials. Subsequently the atmospheric stability may be increased in the lower boundary layer.

On the other hand, it should be pointed out that the lower single scattering albedo obtained in this study is at least in part due to the retrieval errors. The single scattering albedo from the Aerosol Robotic Network (AERONET) sunphotometer observations (Holben et al. 2001) at Anmyon is higher than those obtained in this study, even though the temporal coverage of AERONET retrievals on 7 April 2000 at Anmyon was limited for non-dust aerosols after 6:00 UTC (not shown). It is generally thought that the inversion software used in this study, i.e., SKYRAD.pack version 3 (Nakajima et al. 1996) for estimating the aerosol optical parameters, yields the lower single scattering albedo. Thus the use of the SKYRAD.pack software may be one of reasons causing such a smaller single scattering albedo, suggesting that a caution should be exercised about absolute values of single scattering albedo, and its associated aerosol radiative forcing.

\section{Acknowledgments}

The authors wish to thank the Korean Meteorological Administration (KMA) for generously providing the GMS imagery used in this study. CERES data were obtained from the Atmospheric Sciences Data Center at NASA Langley Research Center. MJC was financially supported by the Subprograma Ciência e Tecnologia do $2^{\circ}$ Quadro Comunitário de Apoio and BJS has been supported by the Korean Geostationary Program (COMS) granted by the KMA. This work was initiated under the bilateral agreement CNR-Italy and KOSEF-Korea: Characterization of atmospheric aerosols from satellite: synergy from polar and geostationary platforms for the Korean area.

\section{References}

Aoki, K. and Y. Fujiyoshi, 2003: Sky radiometer measurements of aerosol optical properties over Sapporo. Japan. J. Meteor. Soc. Japan, 81, 493-513.

Burrows, J.P., M. Weber, M. Buchwitz, V. Rozanov, A. Ladstätter-Weibenmeyer, A. Richter, R. DeBeek, R. Hoogen, K. Bramstedt, K.-U. Eichmann, and M. Eisinger, 1999: The Global Ozone Monitoring Experiment (GOME): Mission concept and first scientific results. J. Atmos. Sci., 56, 151-175.

Chameides, W.L., H. Yu, S.C. Liu, M. Bergin, X. Zhou, L. Mearns, G. Wang, C.S. Kiang, R.D. Saylor, C. Luo, Y. Huang, A. Steiner, and F. Giorgi, 1999: Case study of the effects of atmospheric aerosols and regional haze on agriculture: An opportunity to enhance crop yields in China through emission controls. Proceedings of the National Academy of Sciences, 96, 13,626-13,633.

Clarke, A.D., Y. Shinozuka, V.N. Kapustin, S. Howell, B. Huebert, S. Doherty, T. Anderson, D. Covert, J. Anderson, X. Hua, K.G. Moore II, C. McNaughton, G. Carmichael, and R. Weber, 2004: Size distributions and mixtures of dust and black carbon aerosol in Asian outflow: Physiochemistry and optical properties. J. Geophys. Res., 109(D15), D15S09, doi:10.1029/ 2003JD004378.

Costa, M.J., M. Cervino, E. Cattani, F. Torricella, V. Levizzani, A.M. Silva, and S. Melani, 2002: Aerosol characterization and optical thickness retrievals using GOME and METEOSAT satellite data. Meteor. Atmos. Phys., 81, 289-298.

, 2004: Aerosol and cloud satellite remote sensing: monitoring and modelling using passive sensors. Ph.D. thesis, Dept. of Physics, University of Évora, Évora, Portugal, 233pp. , A.M. Silva, and V. Levizzani, 2004a: Aerosol 
characterization and direct radiative forcing assessment over the ocean. Part I: Methodology and sensitivity analysis. J. Appl. Meteor., 43, 1799-1817.

—, V. Levizzani, and A.M. Silva, 2004b: Aerosol characterization and direct radiative forcing assessment over the ocean. Part II: Application to test cases and validation. J. Appl. Meteor., 43, 1818-1833.

Holben, B.N., D. Tanré, A. Smirnov, T.F. Eck, I. Slutsker, N. Abuhassan, W.W. Newcomb, J.S. Schafer, B. Chatenet, F. Lavenu, Y.J. Kaufman, J. Vande Castle, A. Setzer, B. Markham, D. Clark, R. Frouin, R. Halthore, A. Karneli, N.T. O’Neill, C. Pietras, R.T. Pinker, K. Voss, and G. Zibordi, 2001: An emerging groundbased aerosol climatology: Aerosol optical depth from AERONET. J. Geophys. Res., 106, 12067-12097.

Husar, R.B., D.M. Tratt, B.A. Schichtel, S.R. Falke, F. Li, D. Jaffe, S. Gassó, T. Gill, N.S. Laulainen, F. Lu, M.C. Reheis, Y. Chun, D. Westphal, B.N. Holben, C. Gueymard, I. McKendry, N. Kuring, G.C. Feldman, C. McClain, R.J. Frouin, J. Merrill, D. DuBois, F. Vignola, T. Murayama, S. Nickovic, W.E. Wilson, K. Sassen, N. Sugimoto, and W.C. Malm, 2001: Asian dust events of April 1998. J. Geophys. Res., 106, 18,317-18,330.

Kim, D.-H., B.J. Sohn, T. Nakajima, T. Takamura, 2005: Aerosol radiative forcing over East Asia determined from ground-based solar radiation measurements. J. Geophys. Res., 110, D10S22, doi:19.1029/2004JD004678.

, T. Takemura, B.-C. Choi, and S.-C. Yoon, 2004: Aerosol optical properties over east Asia determined from ground-based sky radiation measurements. $J$. Geophys. Res., 109, D02209, doi:10.1029/ 2003JD003387.

King, M., Y. Kaufman, D. Tanré, and T. Nakajima, 1999: Remote sensing of tropospheric aerosols from space: Past, present, and future. Bull. Amer. Meteor. Soc., 80, 2229-2259.

Masuda, K., Y. Mano, H. Ishimoto, M. Tokuno, Y. Yoshizaki, and N. Okawara, 2002: Assessment of the nonsphericity of mineral dust from geostationary satellite measurements. Remote Sens. Environ., 82, 238-247.

Moulin, C., F. Guillard, F. Dulac, C.E. Lambert, 1997: Long-term daily monitoring of Saharan dust load over ocean using METEOSAT
ISCCP-B2 data: 1. Methodology and preliminary results for 1983-1994 in the Mediterranean. J. Geophys. Res., 102, 16947-16958.

Nakajima, T., G. Tonna, R. Rao, R. Boi, Y. Kaufman, and B. Holben, 1996: Use of sky brightness measurements from ground for remote sensing of particulate polydispersions. Appl. Opt., 35, 2672-2686.

Porcù, F. and V. Levizzani, 1992: Cloud classification using METEOSAT VIS-IR imagery. Int. J. Remote Sens., 13, 893-909.

Shettle, E.P., 1984: Optical and radiative properties of a desert aerosol model. International Radiation Symposium (IRS): Current problems in atmospheric radiation. G. Fiocco Ed., 74-77, A. Deepak, Hampton, Va.

Sokolik, I.N. and O.B. Toon, 1999: Incorporation of mineralogical composition into models of the radiative properties of mineral aerosol from UV to IR wavelengths. J. Geophys. Res., 104, 9423-9444.

Streets, D.G., T.C. Bond, G.R. Carmichael, S.D. Fernandes, Q. Fu, D. He, Z. Klimont, S.M. Nelson, N.Y. Tsai, M.Q. Wang, J.-H. Woo, and K.F. Yarber, 2003: An inventory of gaseous and primary aerosol emissions in Asia in year 2000. J. Geophys. Res., 108(D21), 8809, doi:10.1029/ 2002JD003093.

Sun, J., M. Zhang, and T. Liu, 2000: Spatial and temporal characteristics of dust storm in China and its surrounding regions, 1960-1999. J. Geophys. Res., 106, 10,325-10,333.

Torricella, F., E. Cattani, M. Cervino, R. Guzzi, C. Levoni, 1999: Retrieval of aerosol properties over the ocean using GOME measurements: Method and applications to test cases. J. Geophys. Res., 104, 12085-12098.

Vermote, E.F., D. Tanré, J.-L. Deuze, M. Herman, and J.-J. Morcrette, 1997: Second simulation of the satellite signal in the solar spectrum: An overview. IEEE Trans. Geosci. Remote Sens., 35, 675-686.

Wielicki, B.A., B.R. Barkstrom, E.F. Harrison, R.B. Lee III, G.L. Smith, and J.E. Cooper, 1996: Clouds and the Earth's Radiant Energy System (CERES): An Earth Observing System Experiment. Bull. Amer. Meteor. Soc., 77, 853-868.

Yoshino, M., 2002: Secular variations of sand-dust storm and blown sand occurrence in the Taklimakan desert, NW China. J. Arid Land, 11, 253-258. 